\title{
MILITARY NAMES IN SOUTH AFRICA - QUO VADIS?
}

\author{
(ADDRESS DELIVERED AT FIRST MILITARY NAMES CONGRESS \\ HELD AT FORT KLAAPERKOP ON 30 OCTOBER 1993)
}

Brig (Dr) J.H. Picard*

\section{THE CULTURES OF CLASSES AND MUSTERINGS}

Traditionally society was divided into four classes: priest, soldier, tradesman and worker, and countries such as India have reflected this division for centuries in their societies. Each of these musterings has over the centuries developed its own culture: the priest by way of ethics, liturgy and religious orders, the soldier with his regimental systems, organisations and traditions, etiquet, terminology and rank hierarchy, the tradesman with his guilds, chambers of commerce, advertising and share markets, the worker with his trade unions and worker associations.

Although the modern world has become so specialised that there is no longer such a sharp demarcation between the main musterings, the aspect of a unique culture has remained very important, particularly in the military profession where its unique military customs, regimental traditions, military bands, colourful parades, uniforms and military language and terminology do so much to create a sense of solidarity, pride and comradeship amongst its members.

Language communication is vital to any defence force and in South Africa with its eleven main and many more unofficial languages this is particularly so. Simply put, language comprises a grammatical and lexical component. Where the former represents the language mechanics, the latter constitutes the cultural language dynamics. Names, which comprise the major part of the lexicon of a language are largely culturally conditioned. If you wish to understand a people you must know its names: proper names, common names, names of places, of people, of objects, of weapons, of musical instruments, of activities, rites and processes. Onomastics is the discipline encompassing all naming and related research activities: toponymy, etymology, etc.

\section{THE IMPORTANCE OF NAMES TO THE MILITARY}

The SA Defence Force must have a thorough knowledge of names and their correct use in order to protect itself against cultural faux pas that could cost it the goodwill and support of the local population. For instance, the knowledge of "holy" or "protected" tribal areas, springs, lakes (such as the Fundudzi lake in Vendaland where no women are permitted) is essential for military planning staffs, ethnologists, teachers and language officers.

The knowledge of placenames or toponymy is of the utmost importance for it not only imparts historical and cultural knowledge of the people concerned but also refers to geographical knowledge so important for military tactics and strategy. Obviously, incorrect naming and poor geographical and cultural knowledge could have catastrophic results for a defence force.

The naming of military units, weapons, towns, streets and buildings is an important function which has to be done most judiciously. This is necessary because names are important to people: your name is the one feature distinguishing you from your fellowmen and you set great store by it. In this regard personal names, nicknames and forms of address are vital, particularly in the light of the heterogeneous cultures we have in our country. Unit names are also very important to the military and the Directorate of Documentation 
Services applies a specific SADF names policy in this regard. Such procedure is, of course, not restricted to the military: the City of Pretoria has an advisory Committee on place and street names comprising city councillors and prominent academics who advise the Council on the correct policy and its application to the naming of streets. suburbs, buildings, etc.

The study of names involves many linguistic disciplines: morphology, semantics, spelling, etymology, syntax (including all elements of onomastics, compounds, derivations) and toponymy. The study of names, people and things provides important guidelines for the anthropologist, ethnologist, geographer, linguist and town planner.

Toponymy is very important for many military disciplines: For the military historian those place names given by people who left no documentary records provide essential guidelines to the past. This is particularly important in this period of change when the South African history books are being rewritten to cover the social history of all the RSA's peoples. Research into place names also provides much valuable evidence for the archaeologist of the prehistory of those people originally responsible for naming certain places and areas and it often reveals traces of ancient social and juridical organisational structures. The study of place names also gives clues to the tracks and routes followed by the original travellers, hunters and warriors; this enables the historian or military intelligence officer to identify the movements of peoples, or study the stages of development of a civilisation or group of people.

Toponymy gives clues to the ethnologist of the tribes and peoples who inhabited certain regions and so enables him to accurately determine their geographical distribution. This is particularly important to the politician and the administrator for it has often happened in the past that colonial powers drew their regional borders right across tribal areas. In this way groups that originally belonged together were split up. This gave rise to regular border crossings by people which made adminis- trative and military control almost impossible and lateron created serious problems. Consider the case, for instance, of the working father who each night has to cross a geographic border to get back to his family. For the administrative authorities duplications of names for different areas, places or streets give rise to great problems in postal delivery, communication and geographical identification.

For the military anthropologist or ethnologist there is virtually no area of local culture, thinking, customs or expressions which is not already reflected somewhere in the place names given by a local population. Knowledge of these place names contributes to an accurate study of the cultural traditions and customs of the particular population groups, giving the military administration a greatly enhanced ability to understand the local names and hence, to develop a much improved relationship with the local populations.

\section{NAMES AND NAMES POLICY IN THE SADF}

Olifant, Ratel and Eland (tanks and armoured cars), Jakkals (air transportable jeep), Vlakvark (anti-aircaraft system), Buffel, Hippo (armoured personnel cariers), Zebra and Duiker (trucks), Cheetah (fighter aircraft), Rinkhals (mine-protected ambulance), Rooikat (armoured fighting vehicle), Piet Joubert Training Field, Frederik Ernst street (Voortrekkerhoogte): All these are names officially allocated in the SA Defence Force, giving some indication of the variety of things named in a large military organisation. It is important to regularise name giving to avoid the allocation of unsuitable names and to avoid duplication. It would appear that the naming function in the Union Defence Force from its establishment in 1912 up to 1939 was one of the functions of the AdjudantGeneral. From 1940 his administration dealt with this aspect whilst approval of names was vested in the Chief of General Staff. During World War II the Deputy Chief of Staff authorised naming. Official names were initially limited to units. Only at a later stage was this function expanded to also include mili- 
tary buildings, areas and streets. At that stage it was uncertain which criteria were applied but there were obviously two requirements: a. that the name should be apposite, and $b$. that it should not be a duplication of an existing name.

In addition, thorough-going consideration was necessary since a unit's name forms a central component in creating and developing esprit de corps, unit pride and unit traditions. After the war and the subsequent demobilisation of the UDF the procedures for naming were described and certain requirements laid down. During the term of office of the Minister of Defence at the time, F.C. Erasmus, the following procedure for naming was promulgated - a procedure that has not changed much until today: The application for a new name, together with an acceptable motivation was passed through the normal chain of command to the Adjudant-General. There the proposed name was compared with existing names to avoid duplication and to ensure that it did not conflict with those of existing units. The application was then transmitted to the Commandant-General for recommendation and submission to the Minister of $\mathrm{De}$ fence. Then the Minister in terms of Sect 75 (2) of the Defence Act issued a certificate of approval to the Unit, whereupon the Adjudant-General's department informed the headquarters and divisions concerned and published the new name in SA Defence Force Orders.

From 1945 the names of permanent force units were no longer given only in English but also in Afrikaans. In addition. Active Citizen Force regiments were named after famous South African soldiers no longer living, e.g. Gideon Scheepers Regiment, General Kemp Regiment, etc.

In 1959 new directives were issued owing to the reorganisation of the Citizen Force, and to clear up the confusion of Afrikaans medium units named after soldiers having the same names as some of the Commando Groups e.g. "Danie Theron Regiment" in Western Transvaal Command and "Danie Theron" group in Northern Transvaal Com- mand. This led to Citizen force regiments being given geographical names eg. "Regiment Mooirivier" and the Commando groups being named after famous soldiers. This change was unfortunate and prejudicial to creating esprit de corps. In terms of Ministerial authority in 1960 the situation was rectified, some of the units returning to their original names.

When South Africa became a republic, on 31 May 1961, names such as the "Royal Natal Carbineers", "Imperial Light Horse", etc had to be renamed.

The expansion and reorganisation characterizing the SADF in the sixties and seventies required a wider scope of name-giving; this was expanded to also cover military bases, buildings, streets and training fields. Apart from considerations such as unit pride and building morale and solidarity, practical needs required distinguishing names and a uniform policy. Hence, training fields were called after Boer generals: "General De Wet Training Field".

The large number and diverse nature of names submitted by the Arms of the Service to Chief of Staff Logistics (now controlling the names function) necessitated a general policy in respect of naming buildings and streets in military areas (SADF 4/4.77) the first such official promulgated policy.

Name-giving in the SADF received a new impetus and dimension during the unprecedented expansion of the arms industry in the RSA in the seventies when many items of sophisticated weaponry, aircraft, tanks, ships, vehicles were also officially given names: Army combat vehicles after indigenous animals: "Ratel", "Eland": aircraft after indigenous buck and bird species: "Impala", "Albatros": Submarines after famous South African women: "SAS Maria van Riebeeck", etc.

\section{MILITARY DOCUMENTATION SERVICE}

The nuisance of duplication in namegiving as regards Arms of the Service led to the transfer of the names function to a Military Information Bureau 
falling under the Intelligence Division and the promulgation of a comprehensive names policy (SADF Directive $2 / 7 / 1984$ ), also containing guidelines for the naming of products or product ranges.

A framework for an effective SADF names policy was now established to ensure uniformity, at the same time providing for motivated deviations, where necessary. Procedures were now formalized for the sake of effective co-ordination and in the case of armament applications for names had now already to be submitted in the project study phase. This avoided the giving of unsuitable names which during the developmental phase became fixed making later necessary changes very difficult. The procedure relating to the naming of military areas, including townships, was also set out. Such names were first to be approved by the local authority and later had to be approved by the National Place Names Committee falling under the Department of National Education, whereafter the names are published in the RSA official list of place names. Since April 1990 the Military Information Bureau dealing with the names function is known as the Directorate of Documentation Services and falls under the Personnel Staff Division of the SADF.

\section{NAMES SOCIETY SADF}

On 19 March 1990 the Names Society SADF was established as a full branch society of the National Names Society of Southern Africa. The Names Society SADF has as aims the promotion of onomastics and toponymy in the SADF in order to help develop military culture and communication and the management and co-ordination of names projects in the military field. The society also coordinates all names projects in the Transvaal area. The following projects are at present being undertaken:
a. Military Unit Names in the SADF. Col T. Combrinck.
b. Alternative Military Names in the African languages. Maj (D) D. Vorster.
c. Military Place and Street Names in Pretoria. Mr Tom Andrews.

\section{MILITARY NAMES : QUO VADIS}

It is quite apposite that this new fledgling Names Society has organized the first military Names congress. I think I have indicated the great importance of military toponymy. It also is quite obvious that there are other onomastic aspects which also promote military culture. The military population is increasingly representative of all population groups in our country. This means effectively that in addition to Afrikaans and English also the following languages will feature widely: Zulu, Xhosa, Tsonga, Venda, Tswana, Northern Sotho and Southern Sotho. Each of these languages also have their own dialects. It can therefore be expected that unique names will develop (and have in fact in many cases already developed) for SADF functions, parades, peoples, ranks, weapons and tactics. Afrikaans and English speaking members of the SADF must become acquainted not only with the languages but also with these alternative names for military objects and concepts. The SADF is already through its language service providing tuition in the various African languages. But in order to further improve communication and understanding, so necessary for good relations amongst members of the Forces, the alternative names project launched by Maj (Dr) Vorster, is very important indeed. And humourous. Look at some of the following examples: In Northern Sotho the RSM is called "Ditamati" (based on the orange-red badge of rank worn on the sleeve). Military Legal officers are called in Southern Sotho "Bo-Majiane" meaning fellows telling many lies. In Xhosa the RSM is called "Mehlonyoka" (Snake eyes - for nothing escapes the RSM's eyes). And in Tswana a revolver is called "Serope sa koko" (chicken thigh, based on its shape) and the Tswana's call a pub "Leitlhone" (screwed-up eyes based on the fact that as one drinks more one's eyes gradually become slits.

I would like to direct an appeal to all members of the Service and particularly those serving in military units, to collect examples of such alternative names and submit them to Major Vorster at D Lang. 
Military culture is the life blood of a soldier's profession. It engenders pride. esprit de corps, support, assistance and a high morale. And to be able to effectively serve and protect our country these are qualities we can not do without.

Let us make good use of the services of our Names Society - let us support its objectives and development.

As soldiers we should be justly proud of our military names. And because these names come from so many disciplines: our history, military ceremonial, combat, the very uniforms and badges we wear, weapons, geography, military town planning, postal delivery identification points, our etiquet, our parades, our military music, we can all participate. Do so actively and become members of the SADF Names Society. Not only will you build a strong military culture and be able to pass over our traditions to the many prospective soldiers of all our population groups, but you will have lots of fun in doing so.

Names are very sensitive issues. People pin their ideals, visions and philoso- phies on names. Names can and will be abused for personal and political motives. We as Defence Force members must steer away from such matters. We have to be absolutely objective in our namegivings never allowing controversial choices. For the Defence Force as an a-political organisation must never be involved in any polemics or controversy.

In this era of rapid change, also for tr.e SA Defence Force, traditional military culture has become a focal point of stability and reassurance. If the military guild is to maintain its vital uniqueness as expressed by its culture, and wishes to still use it as a rallying point for morale and esprit de corps, the knowledge of military culture, traditions and names must form part of military training courses for promotion in respect of prospective members of the SADF of all population groups and social backgrounds.

- Brig (Dr) J.H. Picard SM, is the Director of SADF Language Service and his articles have appeared regularly in Militaria. 